\title{
Fiber-optic bronchoscope and detection of lung cancer: A five year study
}

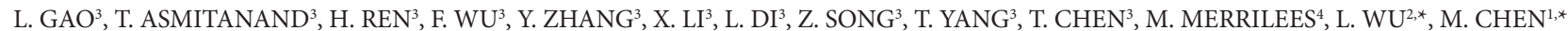

${ }^{1}$ Department of Respiratory Medicine, The First Affiliated Hospital of Medical college of Xi'an Jiaotong University, 277\#, Yanta West Road, Xi'an, 710061, China; ${ }^{2}$ Department of Pharmacology and Clinical Pharmacology, University of Auckland, New Zealand; ${ }^{3}$ Department of Respiratory Medicine, The First Affiliated Hospital of Medical college of Xian Jiaotong University, Xian, 710061, China; ${ }^{4}$ Department of Anatomy with Radiology, University of Auckland, New Zealand

*Correspondence: chenmw36@163.com,l.wu@auckland.ac.nz

\section{Received August 30, 2011 / Accepted October 6, 2011}

\begin{abstract}
White light bronchoscopy [WLB] has been used for identification and localization of intra-epithelial pre-neoplastic and neoplastic lesions within the bronchus. Aim of the study was to evaluate the uses of WLB to detect and localize the precancerous and cancerous lesions, and in addition to analyze morphologic presentation, and association to histological type and the variation between genders.

A total of 4983 patients were examined by WLB from 2004 to 2009 in a local tertiary teaching hospital. The following parameters were collected: morphological presentation, biopsy sites, histology. The patients' records of age, sex, smoking status, blood-gas, X-RAY/CT, CBC, ECG, PT, and APTT were obtained for analysis. Differences between the patients groups were analyzed using Chi square test.

1489 patients who had hyperplasia or neoplasic lesions were further confirmed as having lung cancer pathologically. Lung cancer was more commonly found in the right lung (51.58\% vs $42.82 \%)$. The upper lobe was more frequently found to have lesions ( $44.17 \%$ vs $22.42 \%$ ) than the lower lobe. Male patients with squamous cell carcinoma showed more commonly upper lobe involvement, while left main bronchus was more commonly involved in female patients. Adenocarcinoma was mostly involved in lesions of the upper lobe. Proliferative type was found in $80.15 \%$ of squamous cell carcinoma cases and in $76.16 \%$ of small cell carcinoma cases.

Fiberoptic bronchoscopy is an effective method for the detection of preinvasive neoplasic lesions. The morphological presentation is associated to histological type. There is variation in presentation and histology of cancerous lung lesion between the genders.
\end{abstract}

Key words: bronchoscopy, lung cancer, screening, invasive lesion, gender

Lung cancer is a leading cause of cancer deaths around the world. Both the worsening of the risk factors for the disease and the aging of population may be the two major contributors to current status. Lung cancer has become one of the most common malignant neoplasm in China $[1,2]$. The majority of patients are already in a fairly advanced stage when they first seek medical attention and only $25-30 \%$ of patients can be offered therapeutic resection at most [3]. Characteristically, lung cancer arising from bronchial mucosa (central type lung cancer) at its initial development is radiological occult. The intra-epithelial neoplastic lesions may be asymptomatic and can only be identified by direct visualization at bronchoscopy. Screening test using sputum cytology has been used with limited success [4]. Evaluation of low dose spiral computer tomography (CT) scan as screening tool for lung cancer is being studied [5], and its limitations include high costs, need for repeated scanning and requirement of histological confirmation. Bronchoscopy technique is a promising tool in the early diagnosis of lung cancer in high risk patient groups [6], as it allows to visualize early morphological changes in lung and to take samples for pathological confirmation.

Fiberoptic video bronchoscopy for localization of early neoplastic changes in the bronchial mucosa was clinically introduced in the early 1980s. The method was based on the principle associated with light absorption to provide contrast between normal and abnormal tissue. WLB has reportedly increased the identification and localization of early neoplastic lesions of bronchial mucosa [6]. The established applications of WLB include sputum 
examination, examination of patients with prolonged cough and hemoptysis, follow-up for airway recurrence after surgery, and monitor therapeutic effect on tracheal tumors.

The aim of this study was to evaluate the uses of WLB to detect and localize the precancerous and cancerous lesions, in addition to analyze the morphologic presentation, their association to histological type and the variation between genders.

\section{Patients and Methods}

4983 patients underwent routine WLB examination during 2004 to 2009 at our department. Olympus BF -260, BF-1T260, BF240 bronchofiber videoscopes and EVIS LUCERA system, also from Olympus (Olympus, Japan) were used for the examination. $5 \mathrm{mg}$ diazepam was given 1 hour before examination, followed by $0.5 \mathrm{mg}$ intra-muscular injection of atropine and WLB examination was performed under local anesthesia with three subsequent sprays of $7 \%$ lidocaine each at five minutes interval; the samples were obtained using suitable approach such as forceps biopsy, transbronchial needle aspiration and bronchial brushing with aspiration. 1489 patients were histopathologically confirmed as lung cancer. All the confirmed cases of lung cancer were included into the study. The following parameters were collected: morphologic presentation, biopsy sites, and histology. The patients' records of age, sex, smoking status, blood-gas, X-RAY/CT, CBC, ECG, PT, and APTT were also obtained for analysis.
Statistical analysis. Descriptive data were recorded for all parameters. The clinical variables including pathological and bronchoscope reporting were processed using SPSS 13.0 statistical software, and $\mathrm{X}^{2}$ test was done for relative frequency representation. The $p<0.05$ was considered statistically significant.

\section{Results}

Gender distribution. Among the all patients who underwent WLB, 3314 were male and 1669 were female. Within 1,485 confirmed lung cancer cases, the male to female ratio was 1150:339. The incidence among male patients was significantly higher than in female $\left(X^{2}=109.695, p<0.001\right)$. The results showed 680 patients with squamous cell carcinoma (45.7\%), 375 with adenocarcinoma (25.2\%), 432 with small cell carcinoma (29.0\%), and 2 with adeno-squamous carcinoma (0.1\%). The detection rate for squamous cell carcinoma in males (54.5\%) was significantly higher than that in females $(15.6 \%)$, $\left(X^{2}=159.571, p<0.001\right)$. The incidence of adenocarcinoma and small cell carcinoma was higher in females $(50.2 \%$ and $34.2 \%)$ than in male $(17.8 \%$ and $27.5 \%)$ patients $\left[\left(X^{2}=159.571\right.\right.$, $p=0.001) ;\left(X^{2}=5.775, p=0.016\right)$ respectively] (Table 1$)$.

Age distribution. The incidence of lung cancer was found to relate to age of patients significantly (Pearson correlation coefficient: $r=0.112, \mathrm{p}<0.001)$ (Table3). Pathological con-

Table 1. Pathological type of cancer and variation between the genders

\begin{tabular}{lcccc}
\hline Cancer type & Squamous cell & Adenocarcinoma (\%) & Adeno-squamous (\%) & Small cell (\%) \\
\hline Gender & $(\%)$ & $(\%)$ & $(\%)$ & $(\%)$ \\
\hline Male & $627(54.52 \%)^{*}$ & $205(17.83 \%)^{*}$ & $2(0.17 \%)$ & $316(27.48 \%)^{\triangle}$ \\
Female & $53(15.63 \%)$ & $170(50.15 \%)$ & $0(0 \%)$ & $116(34.22 \%$ \\
Total & $680(45.67 \%)$ & $375(25.18 \%)$ & $2(0.14 \%)$ & $432(29.01 \%)$ \\
\hline
\end{tabular}

Comparison with female: ${ }^{*}$ Squamous cell $\left(\mathrm{x}^{2}=159.571, \mathrm{P}<0.001\right) ;{ }^{*}$ Adenocarcinoma $\left(\mathrm{x}^{2}=145.163, \mathrm{P}<0.001\right) ;{ }^{\triangle}$ Small cell carcinoma $\left(\mathrm{x}^{2}=5.775, \mathrm{P}=0.016\right)$

Table 2 Pathological cancer types in subjects and distribution between age groups

\begin{tabular}{|c|c|c|c|c|c|c|c|c|}
\hline \multirow[t]{2}{*}{ Cancer type } & \multicolumn{4}{|c|}{ Male (\%) } & \multicolumn{4}{|c|}{ Female (\%) } \\
\hline & $<40$ year & 40-59 year & $\geq 60$ years & Total & $<40$ year & 40-59 year & $\geq 60$ years & Total \\
\hline Squamous cell & $15(2.39)$ & $264(42.11)$ & $348(55.5)$ & 627 & $3(5.66)$ & $19(35.85)$ & $31 \quad(58.49)$ & 53 \\
\hline Adenocarcinoma & $7(3.41)$ & $87(42.44)$ & $111(54.15)$ & 205 & $12(7.06)$ & $78(45.88)$ & $80(47.06)$ & 170 \\
\hline Small cell & $17(5.38)$ & $160(50.62)$ & 139 (43.99) & 316 & $8(6.9)$ & $57(49.14)$ & $51(43.97)$ & 116 \\
\hline Adeno-squamous & 1 & 0 & 1 & 2 & 0 & 0 & 0 & 0 \\
\hline Total & $40(3.48)$ & $511(44.43)$ & $599(52.09)$ & 1150 & $23(6.78)$ & $154(45.43)$ & $162(47.79)$ & 339 \\
\hline
\end{tabular}

Table 3 Correlation between age and pathological types of lung cancer

\begin{tabular}{lccc}
\hline Age (years) & Squamous cell carcinoma (\%) & Adenocarcinoma (\%) & Small cell carcinoma (\%) \\
\hline$<40$ & $18(29.03)$ & $19(30.65)$ & Total (\%) \\
$40-59$ & $283(42.56)$ & $165(24.81)$ & $62(100)$ \\
$\geq 60$ & $379(49.87)$ & $191(25.13)$ & $665(100)$ \\
7
\end{tabular}

(Pearson correlation coefficient: $\mathrm{r}=0.112, \mathrm{p}<0.001$ ) 
firmed cancer was mostly among patients above 40 years of age. Patients older than 60 years had a greater prevalence of squamous cell carcinoma and adenocarcinoma. Within patients older than 60 years, squamous cell carcinoma was found in $55.5 \%$ of male patients and in $58.5 \%$ of female patients, and adenocarcinoma was found in $54.2 \%$ of male patients and in $47.1 \%$ of female patients. Small cell carcinoma was more commonly found in patients between 40 to 59 years of age (male: female ratio was 50.6\%:49.1\%) (Table 2, Table 3).

Location of lesion. Lesion was more commonly found in right lung $(773,51.9 \%)$ than in left lung $(643,43.2 \%),\left(X^{2}\right.$ $=194.074, p<0.001)$. Lesion was also more frequently found in upper lobe $(688,46.2 \%)$ than in lower lobe $(342,23.0 \%)$. The right upper lobe lesion was more common than left upper lobe lesion. For male patients, squamous cell carcinoma was more frequently found in upper lobe involvement, however, squamous cell carcinoma was more frequently found in left main bronchus in female patients. Adenocarcinoma was mostly found in upper lobe. For male patients, small cell lung cancer was more frequently found in the right and left upper lobes, however, for female patients, small cell cancer was more commonly presented in right upper, middle and left upper lobe. Involvement of the trachea and carina was seen in 16 patients, of which 10 cases were of squamous cell carcinoma. Multiple lobe involvement was seen in 53 patients, and included 18 cases of squamous cell carcinoma, 18 cases of small cell cancer, and 17 cases of adenocarcinoma. Bilateral lung field involvement was found in 4 cases (Table 4 ).
Morphologic presentation and Microscopic view. 1023 cases of hyperplasia (68.7\%) were observed, and these had multiple patterns (mainly nodular, cauliflower-like, polyploidy and irregular). 391 cases of invasive lesion (26.3\%) showed mucosal roughening, congestion, edema, erosion, necrosis, and purulent secretion under the microscope. 50 cases of compression (3.4\%) and 25 cases with normal presentation (1.7\%) were observed. Proliferative type of cancer was found in $80.2 \%$ of squamous cell carcinoma cases and in $76.2 \%$ of small cell carcinoma (Table 5).

\section{Discussion}

In previous study, less than $15 \%$ of all patients survive five years after a diagnosis of lung cancer [6]. Due to the absence of a reliable screening program, less that $15 \%$ of patients are diagnosed with an early stage I of cancer. In China and across the globe, $80 \%$ of patients are ineligible for surgical resection at diagnosis, mostly because of advanced stage of cancer and poor general condition. Among the methods used for diagnosis of lung cancer, bronchoscopy serves as an important tool involved with diagnosis, staging, and management of lung cancer [7]. Technological improvements have allowed newer modalities to evaluate endobronchial, parenchyma, and mediastinal pathology [8]. However, conventional techniques such as white light video bronchoscopy and its ancillary procedures (forceps biopsy, brush biopsy, bronchoalveolar lavage, bronchial washings, and transbronchial needle aspiration) are still reliable routine methods to determine tumor location,

Table 4 Location, morphologic presentation, and pathology of the lesion

\begin{tabular}{|c|c|c|c|c|c|}
\hline Location & Squamous cell & Adenocarcinoma & Adenosquamous & Small cell & Total \\
\hline Trachea \& Carina & $10(1.47)$ & $3(0.8)$ & 0 & $3(0.69)$ & $16(1.07)$ \\
\hline Left main bronchus & $74(10.88)$ & $16(4.27)$ & 0 & $36(8.33)$ & $126(8.46)$ \\
\hline Left upper lobe & $169(24.85)$ & $80(21.33)$ & 1 & $95(21.99)$ & $345(23.17)$ \\
\hline Left lower lobe & $71(10.44)$ & $50(13.33)$ & 0 & $51(11.81)$ & $172(11.55)$ \\
\hline Right main bronchus & $45(6.62)$ & $10(2.67)$ & 0 & $16(0.37)$ & 71(4.77) \\
\hline Right upper lobe & $151(22.21)$ & $104(27.73)$ & 1 & $86(19.91)$ & $343(23.04)$ \\
\hline Right middle lobe & $68(10.00)$ & $41(10.93)$ & 0 & $80(18.52)$ & $189(12.69)$ \\
\hline Right lower lobe & $72(10.59)$ & $51(13.6)$ & 0 & $47(10.88)$ & $170(11.42)$ \\
\hline Unilateral lung & $18(2.65)$ & $17(4.53)$ & 0 & $18(4.17)$ & $53(3.56)$ \\
\hline Bilateral lung & $2(0.29)$ & $2(0.53)$ & 0 & $0(0)$ & $4(0.27)$ \\
\hline Total & $680(100)$ & $375(100)$ & 0 & $432(100)$ & $1489(100)$ \\
\hline
\end{tabular}

Table 5. Morphological presentation and pathological lung cancer type

\begin{tabular}{lccccc}
\hline Morphological presentation & Squamous cell (\%) & Adenocarcinoma (\%) & Adenosquamous (\%) & Small cell (\%) & Total (\%) \\
\hline Proliferative & $545(80.15)$ & $147(39.47)$ & 1 & $329(76.16)$ & $1023(68.70)$ \\
Invasive/infiltrative & $115(16.91)$ & $190(50.67)$ & 1 & $85(19.68)$ & $391(26.26)$ \\
Compression & $10(1.47)$ & $24((6.40)$ & 0 & $16(3.70)$ & $50(3.36)$ \\
Normal & $10(1.47)$ & $13(3.46)$ & 0 & $2(0.46)$ & $25(1.68)$ \\
Total & $680(100)$ & $375(100)$ & 2 & $432(100)$ & $1489(100)$ \\
\hline
\end{tabular}


size, and type. This study aimed to evaluate the contribution of the WLB in the diagnosis of lung cancer, on a hospital site over a period of five years.

Transbronchial needle aspiration (TBNA) is a minimal invasive and increasingly utilized technique for reliable diagnose and stage of lung cancer. Large case series [8] have reported a diagnostic accuracy of $70-95 \%$, depending upon several factors including operator and cytopathology expertise. In our study, 4983 patients underwent WLB examination, of which 1489 were found to have hyperplasia or neoplasic lesions in lung by WLB and later pathologically confirmed as lung cancer. The consistence between WLB and pathologically confirmation was $100 \%$. The remaining 3498 patients were pathologically negative and having diagnosed as other lung diseases and later discharged from our hospital. However, we cannot rule out future development of cancerous lesions even in these negative patients.

Lung cancer was more frequently found in male subjects (77.2\%), which is consistent with earlier findings [9-11]. Our results showed that there was a 3.39 times higher possibility of lung cancer in male subjects than in female subjects when they had WLB examination (Table1). Moreover, the incidence of squamous cell carcinoma was $54.5 \%$ in male and $15.6 \%$ in females. One possible explanation to this tendency is that men have much higher prevalence of smoking than women in China [10-17] . Chinese National Tobacco Prevalence Survey in 2002 reported current smoking prevalence of $57.4 \%$ for men and $2.6 \%$ for women [14].

Of the 1489 diagnosed cases of lung cancer, squamous cell carcinoma was $45.7 \%$, small cell carcinoma $29.0 \%$, adenocarcinoma $25.2 \%$, adenosquamous carcinoma $2 \%$. Since WLB examination was quite reliable and accurate, and it should be the initial clinical investigation once clinical features indicate possible bronchial lesion in chest [18]. The female cases had a higher incidence of adenocarcinoma (50.2\%) than small cell carcinoma (34.2\%), which is consistent with earlier findings related to the occurrence of lung cancer type in female subjects $[11,19,20]$. We also observed a yearly increase in the incidence of squamous cell carcinoma among female subjects, perhaps due to the increase of female smoking behavior in China recently [21, 22] (Table 2).

The results show a positive relation between incidence rate of lung cancer and the age of patient. The high incidence of lung cancer among elderly subjects may be related to factors like smoking status, food habit, occupational exposure and infectious diseases [19, 22, 23-25]. Moreover, the lack of observed gender predisposition for lung cancer types among subjects more than 60 years of age supports ours assumption that the elderly in China are predisposed to malignancy [26] (Table 3).

Bronchial carcinomas typically involve main, middle and segmental bronchus. Our results show a higher incidence in right lung and in upper lobe. These findings are possibly related to the variation in vascular, lymphatic and anatomic structures. Earlier study [6] has shown a correlation between morphologi- cal abnormality and pathological types. This study found that morphological patterns of lung cancer were related to cancer types and these findings can be used for preliminary diagnosis before pathological confirmation. Our study found that adenocarcinoma presents with an invasive pattern, while squamous cell carcinoma and small cell carcinoma have a proliferative presentation under the WLB (Table 4, Table 5).

The major limitations of WLB are that some of the early precancerous lesions may have a normal appearance using white light bronchoscopy, and WLB cannot detect lesions in the distal regions of lungs. In the past 10 years, several new methods have been developed in order to improve the detection of early cancerous/precancerous lessions, such as autofluorescence bronchoscopy (AFB), narrow band imaging (NBI), fibred confocal fluorescence microendoscopy (FCFM) and ultrasonic endoscopy. Based on the finding that bronchial mucosae fluoresces in premalignant and malignant tissues to a lesser extent than normal tissues, AFB can provide more precise and more sensitive detection of early lesions using its dual real-time imaging of video white light and AFB. However, AFB also has some limitations as it is unable to differentiate early precancerous lesions from inflammatory changes in the bronchial tree. Another common difficulty of early bronchoscopic detection is related to its limitation to the proximal bronchial tree and difficulty in detecting distal metastatic lesion [27]. Narrow Band Imaging (NBI) is a new imaging modality that can be used to observe microvessel structure by adding a NBI filter on a videoscope. Its advantages include showing micovessels of the bronchial mucosae as black images with high contrast, which can provide better discrimination between dysplasia and regular metaplasia compared to normal AFB. However NBI has no advantage in detection of invasive cancer, as reported in a study with small number of patients [28]. Fibred confocal fluorescence microendoscopy (FCFM) uses a flexible miniprobe with an outer diameter of $1 \mathrm{~mm}$ that is introduced into the working channel of the bronchoscope and applied to the tissue. The major advantage of FCFM is that it can produce very precise microscopic fluorescent images of the bronchial basement membrane zone in real time. It can be used to study specific basement membrane remodeling alternations or malignant/premalignant alterations. Another advantage of FCFM is the use of the miniprobe to image distal structures in vivo, such as the alveolar ducts, and intra-acinar sacs. However, it cannot clearly separate the different grades of progression of the precancerous bronchial lesions, such as metaplasia/dysplasia/cancinoma in situ, from each other. Using non-toxic dye may be a solution, however, further studies and confirmations are required to test this new technique [29]. Endobronchial ultrasound (EBUS) has advantages in staging lung cancer and the diagnosis of malignant and benign mediastinal lymphadenopathies. Currently, the negative predictive value of EBUS is still inferior to mediastinoscopy. EBUS requires extra training beyond conventional bronchoscopy. The price and running costs is still higher than mediastinoscopies [30]. 
In conclusion, WLB is an efficient and cost effective method to detect pre-invasive and invasive bronchial cancer lesions. Our study indicates that WLB may still be used routinely in the screening of lung cancer as it can detect early premalignant and malignant lesions by the excellent bronchial mucosa representation. It can precisely locate the correct site for obtaining biopsy samples and can improve the accuracy of pathological confirmation. In the future, the combination of WLB and other techniques will provide more precise and more sensitive detection, and will have ever expanding applications in clinical medicine and research.

\section{References}

[1] YANG L, LI L, CHEN Y, AND PARKIN DM Mortality time trends and the incidence and mortality estimation and projection for lung cancer in China. Zhongguo Fei Ai Za Zhi, 20: 274-278, 2005.

[2] LIZ, YU Y, LU J, LUO Q, WU C, et al. Analysis of the T descriptors and other prognosis factors in pathologic stage I non-small cell lung cancer in China. J Thorac Oncol, 4: 702-709, 2009. http://dx.doi.org/10.1097/JTO.0b013e3181a5269d

[3] HUANG GJ, MAO YS, ZHANG DC, SUN KL, HE J, et al. Current status and future directions of surgery for lung cancer in China. Chin Med J (Engl), 120: 619-621, 2007.

[4] FAN YG, HU P, JIANG Y, CHANG RS, YAO SX, et al. Association between sputum atypia and lung cancer risk in an occupational cohort in Yunnan, China. Chest, 135: 778-785, 2009. http://dx.doi.org/10.1378/chest.08-1469

[5] JIANG T, ZHENG X, TAO X, LIU H, LIU S How to choose PET-CT or CT in the diagnosis and staging of lung cancer. Practical experience in China. Nuklearmedizin, 49: 28-34, 2010.

[6] ESCARGUEL B, D'AMORE D, CHAPEL F, BEC J, AUDIGIERVALETTE C, et al. Early diagnosis of lung cancer: impact of autofluorescence bronchoscopy. Rev Pneumol Clin, 65: 287291, 2009. http://dx.doi.org/10.1016/j.pneumo.2009.04.005

[7] LAM B, WONG MP, FUNG SL, LAM DC, WONG PC, et al. The clinical value of autofluorescence bronchoscopy for the diagnosis of lung cancer. Eur Respir J, 8: 915-919, 2006. http://dx.doi.org/10.1183/09031936.06.00131405

[8] EL-BAYOUMI E, SILVESTRI GA Bronchoscopy for the diagnosis and staging of lung cancer. Semin Respir Crit Care Med, 29: 261-270, 2008. http://dx.doi.org/10.1055/s-20081076746

[9] IWANO S, IMAIZUMI K, OKADA T, HASEGAWA Y, et al. Virtual bronchoscopy-guided transbronchial biopsy for aiding the diagnosis of peripheral lung cancer. Eur J Radiol, 79: 155-159, 2011. http://dx.doi.org/10.1016/j.ejrad.2009.11.023

[10] KAWARAYA M, GEMBA K, UEOKA H, NISHII K, KIURA $\mathrm{K}$, et al. Evaluation of various cytological examinations by bronchoscopy in the diagnosis of peripheral lung cancer. $\mathrm{Br}$ J Cancer, 89: 1885-1888, 2003. http://dx.doi.org/10.1038/ sj.bjc. 6601368

[11] ZENG Y, LIANG J, SHEN H The characteristics of lung cancer cases in 1996-2005 in Nanjing, China. Zhongguo Fei Ai Za Zhi, 11:406-409, 2008.
[12] GAN Q, SMITH KR, HAMMOND SK, HU TW Disease burden of adult lung cancer and ischaemic heart disease from passive tobacco smoking in China. Tob Control. 16: 417-422, 2007. http://dx.doi.org/10.1136/tc.2007.021477

[13] ZOU XN, JIANG JM, LIU BQ, ZENG XJ, WU YP, et al. Study on the relations between smoking and the risk of age-specific lung cancer deaths in urban and rural areas of China. Zhonghua Liu Xing Bing Xue Za Zhi, 30: 907-910, 2009.

[14] LIN HH, MURRAY M, COHEN T, COLIJN C, EZZATI M Effects of smoking and solid-fuel use on COPD, lung cancer, and tuberculosis in China: a time-based, multiple risk factor, modelling study. Lancet. 372: 1473-1483, 2008. http://dx.doi. org/10.1016/S0140-6736(08)61345-8

[15] JIANG J, LIU B, NASCA PC, CHEN J, ZENG X, et al. Age-related effects of smoking on lung cancer mortality: a nationwide case-control comparison in 103 population centers in China. Ann Epidemiol, 18: 484-491, 2008. http://dx.doi.org/10.1016/ j.annepidem.2008.01.004

[16] HU J, GALEONE C, LUI R, PELUCCHI C, LA VECCHIA C, et al. Smoking and lung cancer in Harbin, northeast China. Ann Oncol, 16:1605-1608, 2005. http://dx.doi.org/10.1093/annonc/mdi312

[17] XIN Y, QIAN J, XU L, TANG S, GAO J, et al. The impact of smoking and quitting on household expenditure patterns and medical care costs in China. Tob Control, 18: 150-155, 2009. http://dx.doi.org/10.1136/tc.2008.026955

[18] YAN J, XIAO S, OUYANG D, JIANG D, HE C, et al. Smoking behavior, knowledge, attitudes and practice among health care providers in Changsha city, China. Nicotine Tob Res, 10: 737744, 2008. http://dx.doi.org/10.1080/14622200801901930

[19] YUNG RC Tissue diagnosis of suspected lung cancer: selecting between bronchoscopy, transthoracic needle aspiration, and resectional biopsy. Respir Care Clin N Am, 9: 51-76, 2003. http://dx.doi.org/10.1016/S1078-5337(02)00083-7

[20] LIANG H, GUAN P, YIN Z, LI X, HE Q, et al. Risk of lung cancer following nonmalignant respiratory conditions among nonsmoking women living in Shenyang, Northeast China. J Womens Health (Larchmt), 18: 1989-1995, 2009. http://dx.doi. org/10.1089/jwh.2008.1355

[21] PRONK A, COBLE J, JI BT, SHU XO, ROTHMAN N, et al. Occupational risk of lung cancer among lifetime non-smoking women in Shanghai, China. Occup Environ Med, 66:672-678, 2009. http://dx.doi.org/10.1136/oem.2008.043695

[22] FINCH K, MA S, QIN D, XIN G, XIA W, et al.: Smoking Knowledge, Attitudes and Behaviors Among Rural-to-Urban Migrant Women in Beijing, China. Asia Pac J Public Health, 22: 342-353, 2010. http://dx.doi. org/10.1177/1010539509335034

[23] XIAO L, YANG J, WAN X, YANG GH What is the prevalence of smoking in China. Zhonghua Liu Xing Bing Xue Za Zhi, 30: 30-33, 2009

[24] YANG L, YANG G, ZHOU M, SMITH M, GE H, et al. Body mass index and mortality from lung cancer in smokers and nonsmokers: a nationally representative prospective study of 220,000 men in China. Int J Cancer, 125:2136-2143, 2009. http://dx.doi.org/10.1002/ijc.24527 
[25] WANG Y, WANG A, JIANG R, PAN H, HUANG B, et al. Human papillomavirus type 16 and 18 infection is associated with lung cancer patients from the central part of China. Oncol Rep, 20: 333-339, 2008.

[26] GALEONE C, PELUCCHI C, LA VECCHIA C, NEGRI E, BOSETTI C, et al. Indoor air pollution from solid fuel use, chronic lung diseases and lung cancer in Harbin, Northeast China. Eur J Cancer Prev, 17: 473-478, 2008. http://dx.doi. org/10.1097/CEJ.0b013e328305a0b9

[27] LEE P, BROKX HA, POSTMUS PE, SUTEDJA TG Dual digital video-autofluorescence imaging for detection of preneoplastic lesions. Lung Cancer 2007; 58: 44-49. http://dx.doi. org/10.1016/j.lungcan.2007.04.009
[28] VINCENT BD, FRAIG M, SILVESTRI GA A pilot study of narrow-band imaging compared to white light bronchoscopy for evaluation of normal airways and premalignant and malignant airways disease. Chest 2007; 131: 1794-1799. http://dx.doi.org/10.1378/chest.06-2794

[29] LAEMMELE, GENET M,LEGOUALHERG, PERCHANT A,LE GARGASSON JF, et al. Fibered confocal fluorescence microscopy (CellviZio) facilitates extended imaging in the field of microcirculation. A comparison with intravital microscopy. J Vasc Res 2004; 41: 400-411. http://dx.doi.org/10.1159/000081209

[30] MEDFORD AR. Endobronchial ultrasound-transbronchial needle aspiration and lung cancer. J R coll Physicians Edinb 2009; 39: 91. 